Note

\section{N-Terminal Amino Acid Sequence of Taka-amylase A from Aspergillus oryzae}

\author{
Hiroko Toda, Kiyoshi Kondo* \\ and Kozo NARITA \\ Institute for Protein Research, Osaka University, \\ Yamadakami, Suita, Osaka 565, Japan
}

Received February 1, 1980

Taka-amylase A (TAA) [EC 3.2.1.1 $\alpha$-1,4-glucan 4glucanohydrolase, Aspergillus oryzae] is a single polypeptide chain of molecular weight of 51,000 consisting of about 470 amino acid residues. ${ }^{11}$ The $\mathrm{N}$ - and C-terminal residues were alanine ${ }^{2)}$ and serine, ${ }^{11}$ respectively. The amino acid sequences of the C-terminal 66 residues $^{3)}$ and the $\mathrm{N}$-terminal few residues ${ }^{4,5}$ were reported. In the present investigation we attempted to elucidate the $\mathrm{N}$ terminal sequence of reduced and carboxymethylated (RCM) TAA by means of an automated sequenator. We report here the sequence of the $\mathrm{N}$-terminal 29 residues of RCM-TAA. Comparing our result with the $\mathrm{N}$-terminal sequences of Bacillus subtilis and hog pancreatic $\alpha$ amylases, no similarity in their $\mathrm{N}$-terminal regions was found, although they exhibit similar enzymatic properties.

TAA from Takadiastase (Aspergillus oryzae) was recrystallized from aqueous acetone ${ }^{6}$ and further purified by chromatography on a DEAE-cellulose column. ${ }^{77}$ The homogeneous enzyme in polyacrylamide gel electrophoresis was reduced and carboxymethylated. ${ }^{83}$

Sequential degradation of the protein was performed according to Edman and Begg ${ }^{9}$ in a Beckman Model $890 \mathrm{C}$ sequencer (Beckman Instrument Co., Palo Alto, CA). In the present study, we used $0.5 \mathrm{M} N, N, N^{\prime}, N^{\prime}$-tetrakis-(2hydroxypropyl)-ethylenediamine buffer (Quadrol) and single cleavage instead of $1 \mathrm{M}$ Quadrol and double cleavage in the fast protein-Quadrol program (No. 72172, described in Beckman sequencer Manual). 2-Anilino-5-thiazolinone derivatives were converted into phenylthiohydantoins (PTHs) in $1 \mathrm{M} \mathrm{HCl}$ at $80^{\circ} \mathrm{C}$ for $10 \mathrm{~min}$. PTH-amino acids were characterized by thin-layer chromatography (TLC) on silica gel plates (Eastman Chromagram Sheet $6060)^{10,11)}$ followed by ninhydrin staining ${ }^{12,13)}$ and by phenanthrequinone test for PTH-arginine. ${ }^{14}$ PTH-amino acids were also analyzed by gas liquid chromatography

* Present address: Research Institute for Microbial Diseases, Osaka University, Yamadakami, Suita, Osaka 565. Japan.
(GLC) (Shimadzu Gas Chromatogram GC-6A). ${ }^{15}$ A dehydro form of PTH-Thr was always detected together with PTH-Thr. PTH-Leu could not be distinguished from PTH-Ile in TLC and their assignments were made by GLC data.

In the first attempt, the lyophilized RCM-TAA ( $24 \mathrm{mg})$ was directly dissolved in the reaction cup of the sequencer by adding $0.7 \mathrm{ml}$ of $n$-heptafluorobutylic acid (HFBA) under spinning the reaction cup and the solution was dried using the sample application program (No. 02772, described in Beckman sequencer Manual). The resulting uniform protein film was subjected to the degradation with the fast protein-Quadrol program. The first 25 residues were characterized by both TLC and GLC. The repetitive yields were $94 \%$ and $97 \%$ for Ala-1 to Ala- 4 and Phe- 13 to Phe-19, respectively, based on the GLC data. However, the UV-absorbing spots, which did not correspond to any PTH-amino acids, appeared on the TLC plates and their amounts increased as the cycle proceeded. Therefore, we could not identify PTH-amino acids beyond the 25 th cycle. These artifacts did not disturb GLC analysis of PTHamino acid because they did not give peaks. These nonPTH materials might be derived from the low solubility of the sample in the coupling buffer and incomplete washing of the sequencing protein film because the protein film took times to be dissolved in Quadrol buffer in the coupling stage and was in gel stage in the washing stage.

In the next experiment, RCM-TAA was modified with Braunitzer's reagent III (3-(isothiocyano)naphthalene-1,5disulfonic acid disodium salt ${ }^{16)}$ to improve the solubility in the coupling buffer prior to the automated degradation. RCM-TAA ( $36 \mathrm{mg}$ ) was dissolved in $3 \mathrm{ml}$ of $1 \mathrm{M}$ Quadrol buffer and solid Braunitzer's reagent (10-fold molar excess over total amino groups) was added. The mixture was incubated at $50^{\circ} \mathrm{C}$ for 60 min under a nitrogen atmosphere. The colloidal protein solution went into a clear solution within $10 \mathrm{~min}$ after addition of the reagent. Ten $\mu$ l of triethylamine was added and the mixture was incubated for $60 \mathrm{~min}$ at $50^{\circ} \mathrm{C}$. The mixture was desalted on a Sephadex G- 25 column $(2 \times 100 \mathrm{~cm})$ with $0.2 \%$ ammonium bicarbonate. The protein fraction was pooled and lyophilized. The modified RCM-TAA $(15.6 \mathrm{mg})$ was dissolved in distilled water and transferred into the spinning cup followed by dryness as described above. The degradation was started at the coupling stage of the normal program.

The modification of RCM-TAA with Braunitzer's reagent III improved remarkably the solubility of the protein in the coupling buffer and reduced the amounts of the background materials at each cycle. The repetitive yield was also improved slightly. Therefore, all PTHamino acids except for the first residue upto the 29th cycle could be identified by both TLC and GLC. The results of the first 25 cycles were identical with those of the first experiment. The sequence of $\mathrm{N}$-terminal 29 residues in RCM-TAA deduced was shown in Fig. 1.

The present result could align four tryptic peptides, whose sequences were previously determined (unpublished 


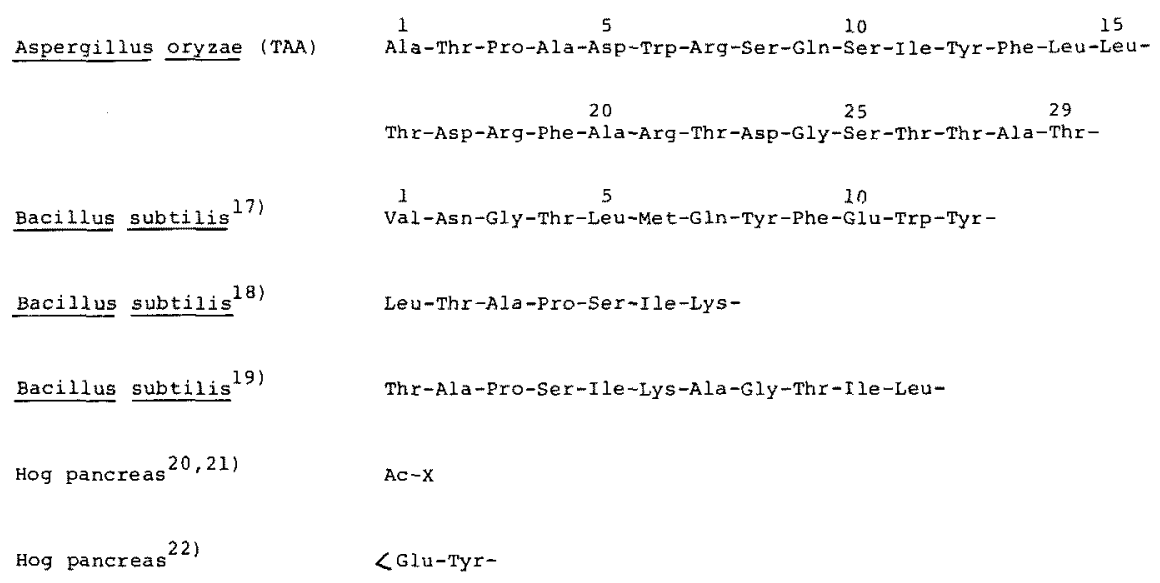

FIG. 1. Comparison of N-Terminal Amino Acid Sequences of $\alpha$-Amylases from Various Sources.

Ac-X shows that the uncharacterized $\mathrm{N}$-terminal residue is blocked with an acetyl group. $<\mathrm{Glu}$ is pyrrolidonecarboxylic acid residue.

results), and was in agreement with the sequence of one of the fragments derived from CNBr-treated RCM-TAA (unpublished results) but was in disagreement with the previously published $\mathrm{N}$-terminal sequence of TAA, AlaGly-Asp- ${ }^{4)}$ and Ala-Gly-Asp-Glu-Ser-Ala-Leu-Thr- ${ }^{51}$ which were deduced by classical method for several 2,4dinitrophenyl (Dnp)-peptides in the partial acid hydrolyzates of Dnp-TAA. Since the present result was obtained by direct sequencing of whole RCM-TAA, the sequence shown in Fig. 1 is believed to be correct.

$\alpha$-Amylase is widely distributed in the plant and animal kingdoms and plays an important role for the use of polysaccharides in vivo. Three $\alpha$-amylases were isolated from different strains of Bacillus subtilis and their $\mathrm{N}$ terminal sequences were reported, ${ }^{17 \sim 19)}$ as shown in Fig. 1. The $\mathrm{N}$-terminal residue of hog pancreatic-amylase was reported to be blocked with an acetyl group, ${ }^{20,21)}$ but recent report described that its isoenzymes have the same $\mathrm{N}$-terminal pyrrolidonecarboxylyl-tyrosine sequence. ${ }^{221}$

By comparing our result with those of bacterial and hog pancreatic $\alpha$-amylases, no sequence similarity in their $\mathrm{N}$ terminal regions was found. This is a striking finding in a viewpoint of structure and function relationship, because these enzymes exhibit the same specificity, catalysis of the hydrolysis of $\alpha-1,4$-glucoside linkage in starch, glycogen and related glucans and have similar enzymatic properties, calcium requirement and optimum $\mathrm{pH}(5 \sim 6) .^{23,24)}$ Therefore we expect that $\alpha$-amylases from different origins have the sequence homologies in the enzymatically functional regions such as active site, calcium binding group and substrate binding site which express the same enzymatic functions and properties.

Further studies to complete the whole amino acid sequence of the enzyme are in progress in our laboratory.
Acknowledgments. We would like to thank Sankyo Co. Ltd. for kindley supplying "Takadiastase Sankyo" and Dr. Titani, K., Department of Biochemistry, University of Washington, Seattle, for his valuable advice for the automated sequencing.

\section{REFERENCES}

1) K. Narita, H. Murakami and T. Ikeneka, J, Biochem., 59, 170 (1966).

2) S. Akabori and T. Ikenaka, J. Biochem., 42, 603 (1955).

3) K. Narita, Proc. Japan Acad, 51, 285 (1975).

4) K. Narita and S. Akabori, J. Biochem., 46, 91 (1959).

5) A. Tsugita, J. Biochem., 46, 583 (1959).

6) S. Akabori, T. Ikenaka and B. Hagihara, J. Biochem., 41, 577 (1954).

7) H. Toda and S. Akabori, J. Biochem., 53, 102 (1963).

8) B. K. Seon, H. Toda and K. Narita, J. Biachem., 58, 348 (1965).

9) P. Edman and G. Begg, Eur. J. Biochem., 1, 80 (1967).

10) J-O. Jeppsson and J. Sjöquist, Anal. Biochem., 18, 264 (1967).

11) T. Inagami, Anal. Biochem., 52, 318 (1973).

12) T. Inagami and K. Murakami, Anal. Biochem., 47, 501 (1972)

13) T. Noda and K. Narita, J. Biochem., 79, 353 (1976).

14) H. D. Nial, "Methods in Enzymology," vol. 27, ed. by C. H. W. Hirs and S. N. Timasheff, Academic Press, New York, 1973, pp. $942 \sim 1010$.

15) J. J. Pisano, "Methods in Enzymology," vol. 25, ed. by C. H. W. Hirs and S. N. Timasheff, Academic Press, New York, 1972, pp. $27 \sim 44$. 
16) G. Braunitzer, R. Chen, B. Schrank and A. Stangl, Hoppe-Seyler's Z. Physiol. Chem., 354, 867 (1973).

17) F. Friedberg and J. Thomsen, Acta Chem. Scand., 28B, 815 (1974).

18) M. Pekka and Z. Howard, J. Biol. Chem., 254, 8540 (1979).

19) Y. Nagata, S. Suga, O. Kado and B. Maruo, Agric. Biol. Chem., 44, 215 (1980).

20) A. T. Ramano and D. H. Strumeyer, Biochim. Biophys. Acta, 446, 19 (1976).
21) P. Cozzone and G. Marchis-Mouren, FEBS Lett., 9 , 341 (1970).

22) I. Kluh, Collect. Czech. Chem. Commun,, 44, 145 (1979).

23) J. A. Thoma, J. E. Sprandlin and S. Dygert, "The Enzymes," 3rd Ed., vol. 5, ed. by P. D. Boyer, Academic Press, New York, 1971, pp. 115 189.

24) T. Takagi, H. Toda and T. Isemura, "The Enzymes," 3rd Ed., vol. 5, ed. by P. D. Boyer, Academic Press, New York, 1971, pp. 235 271. 